Open Access

\title{
Applying action research in CAD teaching to improve the learning experience and academic level
}

Veronica Gracia-lbáñez and Margarita Vergara

\author{
* Correspondence: vgracia@uji.es \\ Departamento de Ingeniería \\ Mecánica y Construcción, \\ Universitat Jaume I, Avda. Sos \\ Baynat, s/n, E12071 Castellón, Spain
}

\begin{abstract}
A project involving innovation in university education is described in this paper. It was implemented in a Computer-Aided Design (CAD) course on the Bachelor's Degree in Industrial Design and Product Development Engineering. Several studies have been published about CAD curricula, yet to the best of our knowledge nothing on applying Action Research (AR) to CAD teaching. The project was carried out over a two-year period, after detecting that academic results were not very good even when the course was not very demanding. In the first year, an experiment based on the AR methodology was planned and put into practice. We took the figure of the teacher-researcher as our own, owing to our conviction that teachers themselves must study their own work and reflect on it critically. Encouraged by the good results, throughout the following year, more changes were made in order to further improve the learning experience. The main actions were to develop self-learning material and to use rubrics for assessment, together with an increase in the level of difficulty in some parts of the evaluation. A detailed chronological description of the actions that were carried out, the implied motivations and both the expected results and those actually obtained are presented.
\end{abstract}

Keywords: CAD, improving academic results, level of difficulty, Action Research methodology

\section{Introduction}

The teaching of Computer-Aided Design (CAD) is such a broad field of study (Asperl, 2005 ) that there is no consensus about what to include in the curricula, since these differ depending on the degree and on the level and age of the CAD learners. Furthermore, some studies (Field, 2004) emphasise the importance of continuing evolution in the training and educational needs of users of CAD systems. From the point of view that today's student is tomorrow's engineer, descriptions have also been put forward regarding what CAD curricula should be like depending on the role CAD will play in the student's future (as a user, an application developer, a software developer or a CAD manager) (Ye, Peng, Chen, \& Cai, 2004). An analysis of the situation of CAD teaching in Spain (Rubio Garcıa R, Gallego Santos R, Suárez Quirós J, Álvarez Peñın PI, 2005) showed that, since the Organic Law of Universities ${ }^{1}$ came into force, each teacher uses different methodologies and tools to teach CAD. In that study, the authors presented

(C) 2016 Gracia-lbáñez and Vergara. Open Access This article is distributed under the terms of the Creative Commons Attribution 4.0 International License (http://creativecommons.org/licenses/by/4.0/), which permits unrestricted use, distribution, and reproduction in any medium, provided you give appropriate credit to the original author(s) and the source, provide a link to the Creative Commons license, and indicate if changes were made. 
the results of a survey about different issues carried out on over 600 teachers. It revealed that, in Spanish universities, there was no agreement on the desirable number of students in the labs, the time to be dedicated to practical sessions, the CAD software to be used or its type (parametric or not) or on the system of evaluation. Hence, the authors classified the ways of assessing students into three groups: by means of practical exercises that are delivered and revised on a weekly base; by means of a final examination in which the student has to solve a problem by using the computer to draw a solution within a given time; or by means of an end-of-year assignment. The tendency seemed to be to give more weight to students' daily work than to the traditional final examinations.

On the other hand, there are also several studies that deal with improving different CAD-related abilities (spatial abilities, visualisation skills or the relationship between 2D drawings and 3D models) using different technologies and methodologies (Contero M, Naya F, Company P, Saorín JL, 2006; Contero M, Naya F, Company P, Saorín JL, Conesa J, 2005; Plumed, Calleja, Varley, \& Martin, 2013). Furthermore, Rossignac (2004) presented some particular examples of teaching CAD based on what he calls education-driven research (EDR). In these examples, new concepts are introduced by mean of analogies or metaphors; expressive notation and evocative names are used to facilitate memorisation, and the focus is placed only on essential aspects, thereby simplifying concepts until they are well understood.

One interesting aspect of teaching CAD (Chester, 2007) is the difference between command knowledge (knowing the tools provided by the software and the procedure for using them) and strategic knowledge (knowing the methods that can be used to achieve a specific task and how to choose one of them), with strategic knowledge being more effective in the development of CAD expertise, especially when no previous CAD instruction has been provided.

Another important aspect in teaching CAD (Asperl, 2005) is the choice of software. Often, CAD software applications have limitations (tools fail to work the way they should, the user interface is not appropriate, the software is not affordable for students, and so forth) that impose a specific way of working.

Knowing exactly how knowledge is transferred and what way of teaching is best for each type of competence will almost certainly lead to an improvement in CAD education. Teaching and researching, understood as an integrated activity, gives rise to the figure of the teacher-researcher. This figure was first noted by Stenhouse (Rudduck \& Hopkins, 1985), a British pedagogue who argued that action research refers to the research conducted by teachers on their own practice in order to find ways to improve students' learning. Teachers' research, he claimed, should also aim to make a contribution to the theory of education that is accessible to other teachers and enters into the critical discourse of the profession (Groundwater-Smith \& Mockler, 2011).

Rudduck and Hopkins (1985) developed a paradigm of action research that aimed to "demystify and democratise research", as a response to their perception that educational research was not contributing effectively to classroom practitioners. It seems pretty clear to us that the best contributions that research in education can make are the contributions that can be transferred to actual educational practice. Although this methodology is well known in the field of Social Sciences, it is still little known in most technological areas such as Engineering (Marqués Andrés \& Ferrández Berrueco, 
2011). The Action Research (AR) methodology (Marqués Andrés \& Ferrández Berrueco, 2011; Riel \& Whitehead, 2011; Riel, 2010) implies following five phases throughout its implementation: identifying the focus, i.e., what we want to improve; analysing the problem or the issues than can be improved; developing an action plan with indicators to measure the impact of the action; carrying out the actions; and, finally, observing and reflecting upon it by analysing the data collected. Successful indicators would point out that the planned action has obtained the expected outcome.

This article presents a case study in which the AR methodology was applied to a CAD course in a particular context (available software, degree, size of lab groups, and education programme). The course is taught to students in the second year of the Bachelor's Degree in Industrial Design and Product Development Engineering at Jaume I University (UJI) in Castellón, Spain. It has been taught for three years since the degree started in the 2011/2012 academic year. The project described here was carried out for the two years following the start of the degree, after detecting that the academic results in the first year were not very good even when the level of difficulty of assessment activities was not very high. This situation is not a desirable one for a committed teacher. In the first year of its implementation (2012/2013), an experiment based on the AR methodology was planned and developed. Encouraged by good results, throughout the second year of its implementation (2013/2014), more changes were made in order to improve the learning experience. A detailed chronological description of the actions carried out, the implied motivations and both the expected results and those actually obtained are presented. Our focus was on finding methodologies to improve academic results while increasing the level of difficulty. If academic results improve, despite a higher level of difficulty of the assessment activities, the learning experience will be better and the target competences will be achieved. Even though the applied AR methodology aims to detect local needs, the changes in methodology and evaluation that have been made are based in the principles of the most ingrained pedagogical theory of knowledge: constructivism, in its different forms (Coll, 1996). We have taken from Piaget the idea that humans have to create their own knowledge (Zaphiris \& Ioannou, 2014), from Ausubel (1968) that we have to start from prior knowledge for learning to be significant, and from Vygotsky (1978) the idea of scaffolded learning. Consequently, our results can be applied to other subjects or situations to improve the learning experience. The main idea is to provide resources to help students achieve significant learning by working on their own and by making their own efforts.

The action plan was intended to be carried out over two years: in the first academic year, the focus was on the practical part, whereas in the second year, the focus was also on the theoretical part. The indicators employed to decide whether the action implemented worked as expected were the academic results (final marks) and the students' perceptions of the planned actions and the teachers' perceptions of the experiment.

\section{Material and methods}

The CAD course is taught in coordination with three other courses of the degree. The global aims of the four coordinated courses, related to Technical Drawing and Graphic Communication, are that students have to develop the following competences and achieve the following learning outcomes: 
- Ability to apply spatial representation systems (multiviews and pictorial projections), and graphic representation techniques.

- Knowledge of descriptive geometry and metric geometry.

- Ability to sketch, and ability to draw and model with CAD.

- Skills and capabilities for engineering technical drawings.

The first two competences, the ability to sketch and some skills for engineering technical drawings are worked on intensively in the first year of the degree, through two one-semester courses (Technical Drawing and Graphics I \& II). In the second year of the degree, in the CAD I course, the one for which we created the experience described here, students have to develop the abilities needed to draw with CAD applications and to improve their skills and capabilities for engineering technical drawings, using mainly the $2 \mathrm{D}$ drawing module of a CAD commercial software package. In the third year, the aim of the CAD II course is to improve those same abilities and skills but instead using 3D modelling (virtual models of products in 3D or virtual prototypes).

The educational programme, or syllabus, of the course must follow certain rules with regard to content, to time dedicated to specific activities (theory and lab classes, personal work) and to evaluation, which were approved in the initial definition of the degree and could not be changed. The content can be summarised as knowledge of CAD tools for generating, editing and sharing engineering drawings, as well as the development of technical drawings with the $2 \mathrm{D}$ drafting module of a widely used commercial CAD system. The study load of the course is 6 ECTS credits and Table 1 shows the number of hours set per activity, including both class attendance and personal work. Finally, with regard to the assessment of the students, the degree establishes a maximum weight of $20 \%$ of the final mark for practical assignments carried out at home, which implies that at least $80 \%$ of the final mark has to be achieved through exams.

Within this context, we have detailed the CAD I curricula in a more specific list that includes typical drawing aids of CAD systems, coordinate systems and geometric transformations of figures, primitives in CAD (groups, layers, advanced primitives such as patterns, text and tables), graphic formats, storage and exchange of information, dimensioning and parametric drawing, curves, schematic drawings, project drawings and an introduction to 3D.

Table 1 Activities scheduled for the CAD I course

\begin{tabular}{|c|c|c|c|}
\hline Activities & $\begin{array}{l}\text { Classroom } \\
\text { hours }\end{array}$ & $\begin{array}{l}\text { Personal } \\
\text { work hours }\end{array}$ & Specific activity (proposed by teachers) \\
\hline Theory & 12 & 0 & Theory sessions ( $12 \times 1$ hours/week) \\
\hline $\begin{array}{l}\text { Practical part (laboratory) } \\
\text { and Tutoring }\end{array}$ & $37+1$ & 0 & $\begin{array}{l}\text { Practical sessions ( } \approx 13 \times 3 \text { hours/week) } \\
\text { including project tutoring }\end{array}$ \\
\hline Evaluation & 10 & 0 & $\begin{array}{l}\text { Practical evaluation ( } 2 \times 3 \text { hours })+ \text { Final Exam } \\
\text { ( } 4 \text { hours) }\end{array}$ \\
\hline Personal work & 0 & 60 & $\begin{array}{l}\text { Weekly voluntary exercises ( } 14 \text { weeks } \times 2.5 \text { hours/ } \\
\text { week) + Graphic Project ( } 25 \text { hours) }\end{array}$ \\
\hline Exam preparation & 0 & 30 & $\begin{array}{l}\text { Theoretical concepts study, solving previous } \\
\text { year's exams }\end{array}$ \\
\hline $\begin{array}{l}\text { Total hours (number } \\
\text { credits } * 25 \text { ) }=150\end{array}$ & 60 & 90 & \\
\hline
\end{tabular}


Table 1 also shows the methodology we followed for each time period and activity. Time spent on attending classes consists of theory sessions presenting general concepts of $\mathrm{CAD}$ according to the detailed curricula, and the related practical sessions where those concepts can be applied. The software used is AutoCAD®, which is available at the university with a campus licence and students can also have a legal copy through the university. In the practical sessions, certain problems are proposed, the commands of the program needed to solve them are presented, and the different ways of solving them are discussed in terms of efficacy to ensure that strategic knowledge can be achieved. Personal work at home includes weekly voluntary exercises (similar to the problems proposed in the lab session) and a mandatory graphic design project, in which technical drawings of an assigned existing product have to be produced (Fig. 1) as an end-of-year assignment.

Given that the weight of the exams in the final mark is so high, there are two midterm practical ones and a final theory and practice one. Hence, the final mark is composed of the mark obtained in the exams and the mark for the graphic project.

During the course prior to carrying out the project, several issues were found:

- Listening to the students, it became quite clear that there was a shortage of learning material.

- From the results obtained, especially the graphic design projects handed in, it was easy to deduce that these results were unsatisfactory, even though the level of difficulty of the assessment activities was not very high.

Hence, we felt compelled to do something. It is important to note that we did not feel compelled to do something because of the desire for students to have good grades. Like

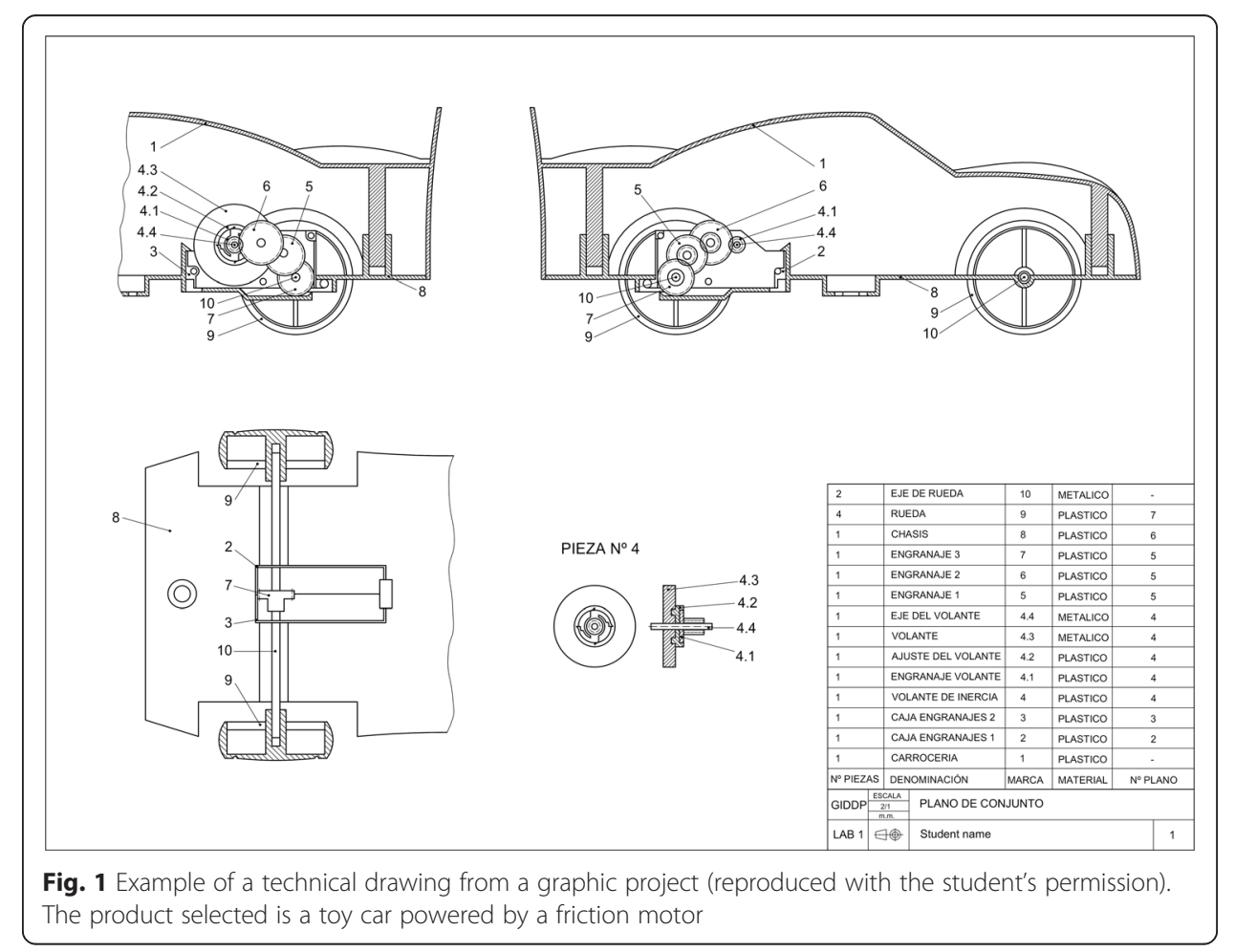


Ken Bain (Bain, 2007), we do not consider good teachers to be those who prepare their students well for an exam, but instead those who expect their students to achieve valuable learning, and that is what we pursue. In the first year of the experiment, we focused on the practical part and greater importance was given to the graphic project in order to reach the desired competences. Both the practical part and the graphic project bear a closer relationship to real problems that students are likely to find in their professional lives.

Our five AR phases were as follows:

Our aim was to find methodologies to improve academic results while increasing the level of difficulty of the assessment activities. If academic results improve, despite a higher level of difficulty, the learning experience will be better and the target competences would probably be achieved (phase 1).

On analysing the problem (phase 2), the action plan (phase 3) was intended to be developed over two years. In the first year, the focus was on the practical part of the subject, whereas the second academic year also focused on the theory part.

Basically, two actions were carried out (phase 4): making changes in the methodology and increasing the level of difficulty of the assessment activities. From the results obtained, an in-depth reflection was made (phase 5) and the conclusions shown in this work were drawn.

Changes in the methodology were taken into account by providing the students with more learning resources. Throughout the first year, some tutorials (Fig. 2) were developed for the practical sessions as learning support material. More than 25 tutorials

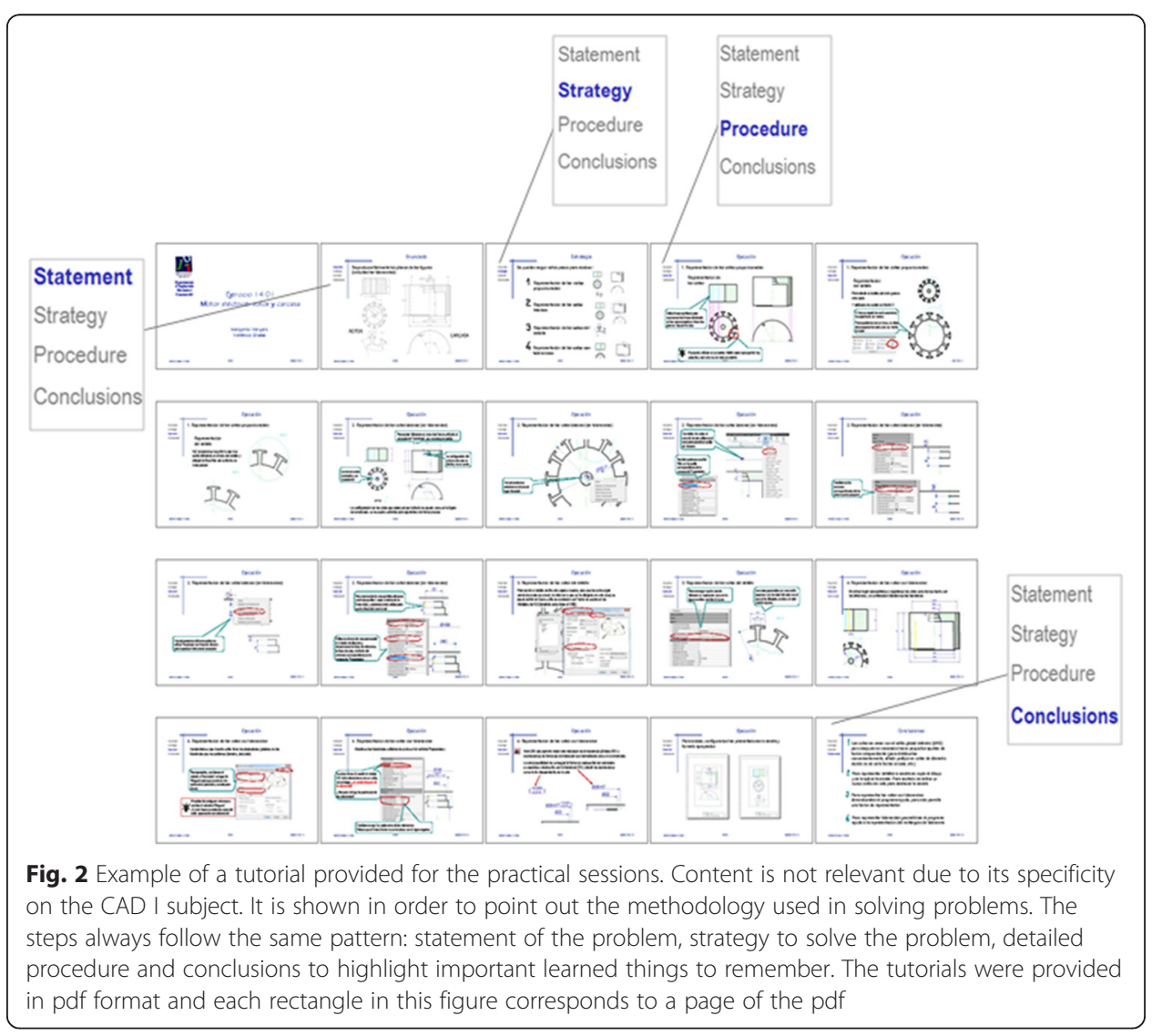


were produced, ranging from 9 to 38 pages. Each tutorial formulates a problem and explains a strategy to solve it and how to do it step by step, emphasising the use of the most appropriate tools in CAD software to achieve it in a more efficient way. Thus, the students could work on their own. They could also review those aspects that had been practised in class. Hence, the action developed was aimed at giving students more information to allow them to undertake self-learning. The experiment focused on constructivist learning, self-learning and meaningful learning (Novak, 2004) through solving problems/real cases (Coll, Mauri, \& Onrubia Goñi, 2006) as methodologies to produce improvements. This should presumably lead to higher academic performance.

Encouraged by the good results obtained in the practical skills in the first year (for a description, see below under Results), the second year of the study was devoted to improving the theoretical skills, also by creating more material or improving it. More than 15 detailed documents were produced, ranging from 15 to 59 pages. In this case, besides the written support for theoretical classes, weekly online self-correcting questionnaires (Fig. 3) were developed as a support to the continuous learning of theoretical concepts.

Furthermore, as supplementary material to help in focusing on the objectives, in the first year, the assessment criteria for the practical exams were clearly specified and explained to students, and in the second year, a rubric for the assessment of the graphic project was also provided (Fig. 4), together with the formulation of the project in order to better guide its execution. It has already been demonstrated that it is of utmost importance to specify the assessment criteria clearly (Sanmartí, 2007).

Regarding the second action carried out, we increased the level of difficulty in two directions, by means of insisting on higher quality in the graphic project and also by requiring a minimum mark.

In the first year of its implementation, we increased the difficulty of the assessment activities, both in terms of the quality of the graphic design project and in the exams. The level of difficulty for the project was increased by requiring more quality and content and, in the exams, by requiring a minimum mark of 4 out of 10 in each part. In the second year, the requirement of 4 out of 10 was also added in the project.

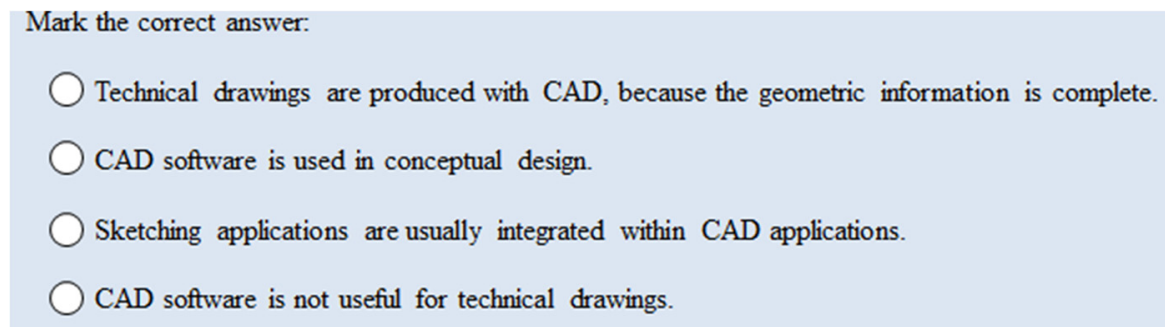

Blocks are files which are saved either as independent files or within the file itself as an entity or special primitive:

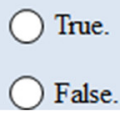

Fig. 3 Example of some of the questions on the weekly online self-correcting questionnaires (12 questionnaires with 7 to 14 questions in each one) 
Project Evaluation Rubric:

Each of these items is evaluated as Perfect / Fair / Incorrect. All the items have the same rating. The items marked with * are optional: they are used only to improve the grade.

Items about paper delivery:

- Order, folding and presentation of drawings

- Title block is fully labelled

- Visibility of lines (colour and selection of visible lines)

- Appropriate sizes and orientations of the paper

- Appropriate thickness and type of lines

- Appropriate size of dimensions and other annotations

- Other representations well done (perspectives) *

- Other representations well done (tolerances) *

Items about explanation of the product:

- Proper explanation of the assembly and how it works

- Photo with identification of parts and all part names

Items about assembly drawings:

- Bill of materials is complete

- Bill of materials is well drawn

- Marks on all parts

- Marks well delineated (sequence and location of marks)

- Views and sections: All parts are shown

- Views and sections: Sketching of section lines is well represented (angle and spacing)

- Views and sections: Lines are well represented

Items about detailed drawings of simple parts (minimum 2 simple parts per student):

- Enough views and sections to define the shape of the parts

- Fully dimensioned to define the dimensions of the parts

Items about detailed drawings of parts with an intermediate level of difficulty (minimum 2 intermediate parts per student):

- Enough views and sections to define the shape of the parts

- Fully dimensioned to define the dimensions of the parts

Items about detailed drawings of difficult parts (minimum 1 difficult part per student):

- Enough views and sections to define the shape of the parts

- Fully dimensioned to define the dimensions of the parts

Items about Electronic delivery:

- Presentations are identifiable and tidy. Content is easily accessible

- No 'trash' in the electronic file

- Organization of layers

- Use of standardized scales

Fig. 4 Rubric for the Graphic Project

To encourage the students, a higher weight was given to the project in the final mark by increasing the percentage up to the maximum allowed, that is to say, $20 \%$. All these conditions are listed in Table 2.

Objectivity was taken into account by triangulating data when establishing the indicators to decide whether the actions implemented gave the expected results: academic outcomes (final marks), students' perceptions of the planned actions and teachers' perceptions of the experiment. 
Table 2 Evolution of assessment over the years of implementation

\begin{tabular}{|c|c|c|c|c|c|c|c|c|c|c|}
\hline \multirow[b]{2}{*}{ Year } & \multicolumn{5}{|c|}{ First call (January) } & \multicolumn{5}{|c|}{ Second call (June) } \\
\hline & $\begin{array}{l}\mathrm{PE} \\
(\%)\end{array}$ & $\begin{array}{l}\text { GP } \\
(\%)\end{array}$ & $\begin{array}{l}\text { TP } \\
(\%)\end{array}$ & $\begin{array}{l}\mathrm{PP} \\
(\%)\end{array}$ & $\begin{array}{l}\text { Additional } \\
\text { requirements }\end{array}$ & $\begin{array}{l}\mathrm{PE} \\
(\%)\end{array}$ & $\begin{array}{l}\mathrm{GP} \\
(\%)\end{array}$ & $\begin{array}{l}\text { TP } \\
(\%)\end{array}$ & $\begin{array}{l}\mathrm{PP} \\
(\%)\end{array}$ & $\begin{array}{l}\text { Additional } \\
\text { requirements }\end{array}$ \\
\hline $\begin{array}{l}\text { Previous } \\
\text { year }\end{array}$ & 10 & 10 & 32 & 48 & & & & 32 & 68 & \\
\hline \multirow[t]{2}{*}{ First year } & 10 & 20 & 25 & 45 & $\mathrm{TP} \geq 4$ & & & 25 & 75 & $\mathrm{TP} \geq 4$ \\
\hline & & & & & $P P \geq 4$ & & & & & $P P \geq 4$ \\
\hline \multirow{3}{*}{$\begin{array}{l}\text { Second } \\
\text { year }\end{array}$} & 10 & 20 & 25 & 45 & $\mathrm{TP} \geq 4$ & & 20 & 25 & 55 & $\mathrm{TP} \geq 4$ \\
\hline & & & & & $P P \geq 4$ & & & & & $P P \geq 4$ \\
\hline & & & & & $G P \geq 4$ & & & & & \\
\hline
\end{tabular}

PE Practical exercises during course (2), GP Graphic Project

$T P$ Theory part of the final exam, $P P$ Practical part of the final exam

In the case of academic outcomes, an increase in the number of students who pass or an increase of marks would indicate that the actions implemented gave the expected results. First, Pearson's Chi Square tests (Siegel, 1988) were applied to check significant differences in the percentage of students who did or did not pass in the different years. Second, the final marks neither follow normal distributions for the years of implementation (before or after the experiment) nor present homogeneity of variances. Therefore, instead of an ANOVA, a Kruskal-Wallis test (Siegel, 1988) was performed to check whether the distribution of the final marks in the three years was significantly different (dependent variable: the final marks obtained [best mark of each call for all the students, those who passed or not]; independent variable: year of implementation).

The students' and the teachers' perceptions were also taken into account. A survey was conducted in order to include the students' perceptions. The questions included dealt mainly with the usefulness of the learning materials provided and their opinions about the methodology as a whole. In particular, three questions asked about the tutorials of the practical sessions, three about the graphic project and three about the online self-correcting questionnaires. A Likert scale from 1 to 5 was used. Furthermore, open-ended questions were included for all the three aspects and for the midterm exams. All the teachers of the course (three or four depending on the year) had previous and ongoing meetings to coordinate methodology and evaluation criteria and, above all, a final meeting to discuss their individual perceptions about the implementation of the experiment.

\section{Results}

Data obtained from the three viewpoints are presented below.

Figure 5 shows a graph with the percentage of students who passed (out of those who took the exams). An initial Pearson's Chi Square test, with the three years and the number of students who passed or failed, produced a significant value of $p=0.049$ indicating that a significant statistical difference exists. Therefore, to check which years were different (post-hoc), three subsequent Pearson Chi Square tests were performed including each pair of years (to have $2 \times 2$ contingency tables). The significant values were 0.017 for Previous/First Year, 0.724 for Previous/Second Year, and 0.042 for First/ Second Year, which means that statistical differences in the percentage of students that passed the exams exist between the first year of implementation and the other two. 


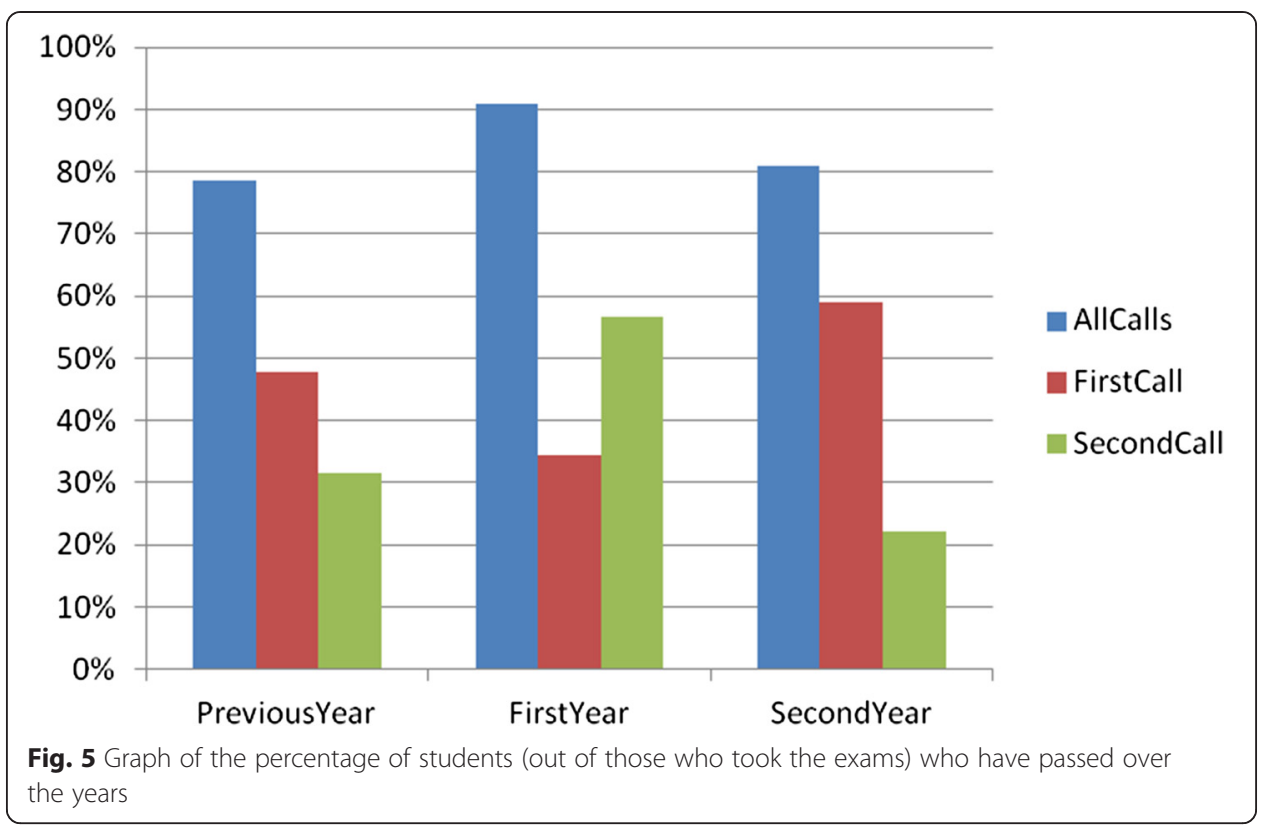

Table 3 shows descriptive statistics of marks across the years of implementation. The results of the Kruskal-Wallis test showed significant differences in the statistical distribution of the marks between the previous year and the other two. The significant values were $<0.001$ for Previous/First Year, $<0.001$ for Previous/Second Year, and 0.821 for First/Second Year. The existence of significant differences between the previous year and the other two years of implementation can be inferred.

Besides the academic results, especially the final marks, two more indicators were also considered: teachers' observations and students' perceptions.

Figure 6 shows the results of the survey conducted on the students, aggregated by methodology (practical tutorials for practical sessions, graphic project and the questionnaires for theory concepts): the confidence interval of mean opinions over the two years of the implementation of the plan.

The open-ended questions also offered some good insights. The main complaint reflected in them was about the (according to them, still too small) weight of the project in the final mark.

\section{Discussion}

From the results obtained and in relation to the first indicator, it can be observed that the percentage of students who passed at all the exam calls increased significantly in the first year of implementation (Fig. 5 and statistical test). However, the percentage of

Table 3 Descriptive statistics of marks: mean and standard deviation, along with quartiles for all students (those who passed and those who did not, considering their best mark in both calls) based on a total of 10 points

\begin{tabular}{lccccc}
\hline Year & Mean & $S D$ & $P_{25}$ & $P_{50}$ & $P_{75}$ \\
\hline Previous year & 5.2 & 1.2 & 5.0 & 5.3 & 5.9 \\
First year & 5.9 & 1.2 & 5.1 & 6.1 & 6.7 \\
Second year & 5.9 & 1.5 & 5.0 & 6.0 & 7.0 \\
\hline
\end{tabular}




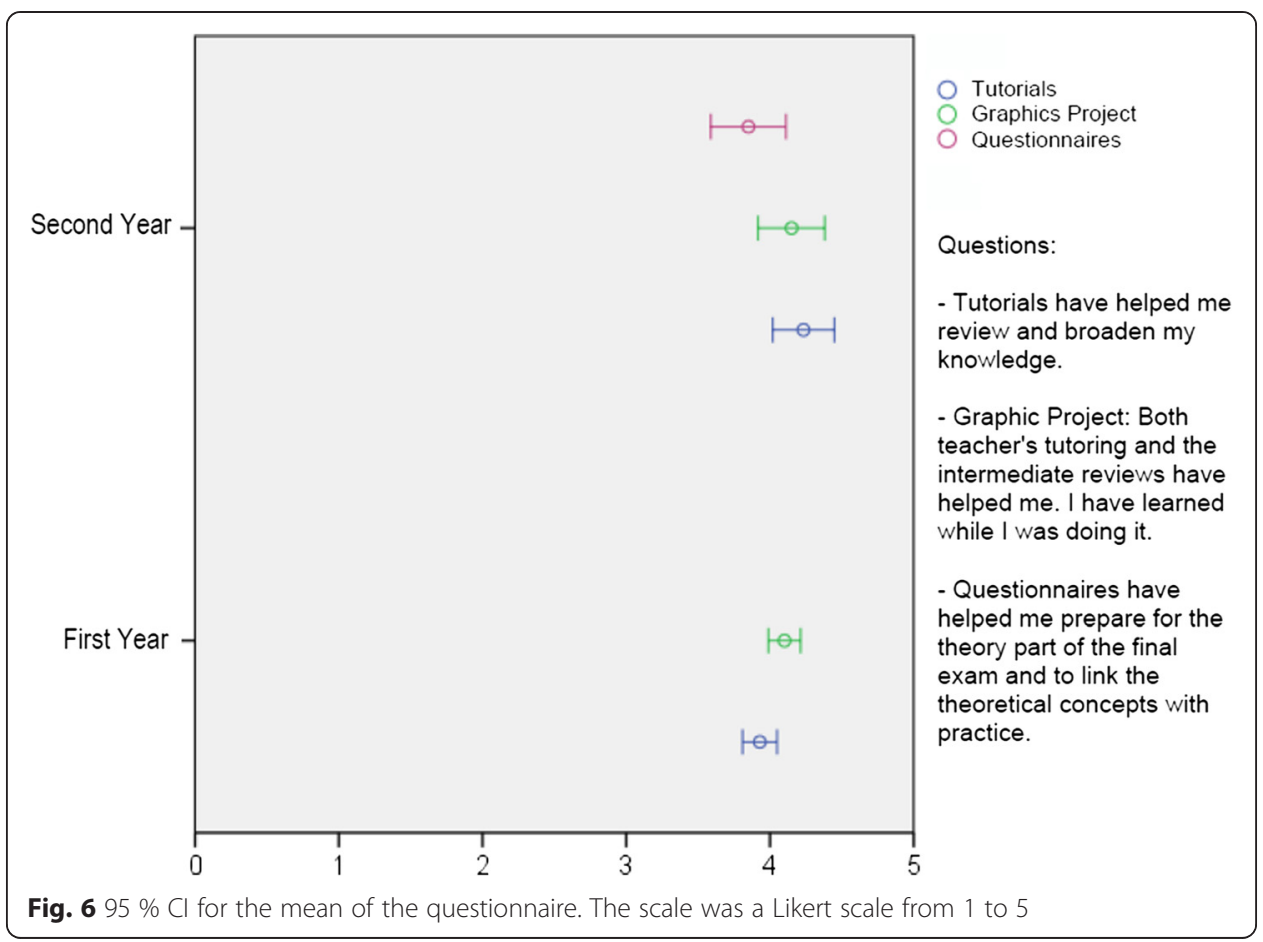

students who passed at the first call in that case was reduced, probably due to the new requirement of the minimum mark of 4 in the theoretical exam without any additional support and the higher level of difficulty in the exam. For the second year of the experiment, the level of difficulty in the theory part was increased, because we expected a better result on the weekly online questionnaires. The number of students who passed increased in comparison to the previous year, but decreased if compared with the first year. This result reinforces the idea that the changes made produced a benefit because of a significant increase of the students who passed among those who took the exam, especially in the first year of the implementation.

Also worthy of note is that despite the more demanding requirements, the percentage of students who passed and the average mark both increased as a result of the implementation of these methodologies. However, what attracts the most attention in this case is that the standard deviation increased in the second year. This may be due to a different reaction of the students when increasing the level of difficulty: those who make a greater effort get higher marks, but those who do not get lower ones; hence there is more variation in the marks. The results from the Kruskal-Wallis test, showing significant differences between marks of the previous year (before the implementation of the experiment) and marks of the first and second years (after the implementation of experiment) reinforces the fact that the experiment carried out produced significant improvements.

The results are in accordance with the ones expected according to literature. The actions carried out tried to support students by means of scaffolding their learning (Vygotsky, 1978) by facilitating ways to create their knowledge. Our purpose was far from simply giving the students knowledge to be accepted and memorised. Instead, it was to give them strategies and resources to make them create their own knowledge and to enable them to use it to solve problems. In Piaget's words: “... education means 
making creators... You have to make inventors, innovators-not conformists" (Bringuier, 1980). Actions taken in this sense seem to have worked properly.

If we take a look at the students' responses to the survey, they indicate a clear acceptance of the methodology. It is stimulating to see that the students' perceptions more or less coincide with the teachers' perception. The teachers observed an improvement in receptivity to the subject by the students and a clear improvement in the level, which was reflected above all in the project in which the level of quality increased, as more complicated products were successfully represented (as can be seen in Fig. 1). Obviously, the students' higher implication and effective work achieved with these actions have been accompanied by a great deal of effort by the teachers. We strongly believe that good levels of coordination among teachers, hard work in preparing valuable material or a thorough description of the evaluation criteria are some of the key points for success. However, all this hard work is highly rewarded when an improvement in the quality of learning and an increase in the students' satisfaction are observed.

\section{Conclusions}

From the experiments carried out, it can be deduced that the methodology employed has produced the expected effects, which means an improvement in academic results despite a higher level of difficulty of the assessment activities. It is remarkable that the perception that students have of the subject has also been improved. Although the experience has been developed in teaching CAD, the methodology may be applied to any specific subject or country.

As a final conclusion we would say that by:

- Providing varied self-learning material

- Detailing evaluation criteria in each part (including the use of rubrics)

- Requiring a higher level (quality, complexity)

- Demanding minimum marks, but giving a mark for everything

better academic results can be achieved, together with a good level of appreciation by students.

\section{Endnotes}

${ }^{1}$ The Organic Law of Universities came into force in 2001 in Spain for defining, among other aspects, the rules for Spanish Universities to adapt their degree courses to the requirements of the European Higher Education Area (Bologna Process).

\footnotetext{
Authors' information

Verónica Gracia-Ibáñez is a lecturer in Computer-Aided Design at Jaume I University (UII) in Castellón, Spain. Her professional background has been in the field of industrial engineering projects. Since her engagement as a parttime lecturer in 2011, she has developed an interest in researching both in the field of biomechanics, in which she is currently working on her PhD thesis, as well as in the field of education, as shown by her participation in two educational innovation projects, two publications at international congresses on education and the co-authorship of a textbook.

Margarita Vergara is Full Professor in Computer-Aided Design and Ergonomics at Jaume I University (UJ) in Castellón Spain. Her professional research interests are biomechanics of the hand and the ergonomic evaluation of product design, as well as ways to improve her teaching. Thus, she has taught Computer-Aided Design and Graphics in different Engineering Degrees for more than 20 years and has authored 18 textbooks. As a result of her interest in improving teaching, she has published one paper in an international peer-reviewed journal and presented 18 communications at congresses and conferences on teaching.
} 


\section{Acknowledgements}

The authors are grateful for support from the Unitat de Suport Educatiu of Jaume I University through project Ref: $2793 / 13$ and for the comments made by the reviewers, which were very helpful.

Received: 3 November 2014 Accepted: 18 May 2015

Published online: 24 February 2016

\section{References}

Asperl, A. (2005). How to teach CAD. Computer-Aided Design and Applications, 2(1-4), 459-468. doi:10.1080/16864360 2005.10738395

Ausubel, D. P. (1968). Educational Psychology: A Cognitive View. Educational psychology a cognitive view. doi:10.1107/ S010827019000508X

Bain, K. (2007). Lo que hacen los mejores profesores universitarios. Traducción de Óscar Barberá: Servicio Publicaciones Universidad de Valencia, Valencia (Spain). ISBN 978-84-370-6669-1.

Bringuier, J. C. (1980). Conversations with jean piaget. Society, 17, 56-61. doi:10.1007/BF02694634

Chester, I. (2007). Teaching for CAD expertise. International Journal of Technology and Design Education, 17, 23-35.

Coll, C. (1996). Constructivismo y educación escolar: ni hablamos siempre de lo mismo ni lo hacemos siempre desde la misma perspectiva epistemológica. Anuario de Psicología, 153-178.

Coll, C., Mauri, T., \& Onrubia Goñi, J. (2006). Análisis y resolución de casos-problema mediante el aprendizaje colaborativo. RUSC. Universities and Knowledge Society Journal, 3(2), 8.

Contero, M., Naya, F., Company, P., \& Saorín, J. L. (2006). Learning support tools for developing spatial abilities in engineering design. International Journal of Engineering Education, 22, 470-477.

Contero, M., Naya, F., Company, P., Saorín, J. L., \& Conesa, J. (2005). Improving visualization skills in engineering education. IEEE Computer Graphics and Applications, 25, 24-31. doi:10.1109/MCG.2005.107

Field, D. A. (2004). Education and training for CAD in the auto industry. Computer-Aided Design, 36(14), 1431-1437. doi: 10.1016/j.cad.2003.10.007

Groundwater-Smith, S., \& Mockler, N. (2011). Speaking of Quality and Research that Counts: Making an Impact on Practice. Action Researcher in Education, 11, 10-18.

Marqués Andrés, M., \& Ferrández Berrueco, R. (2011). Investigación práctica en educación: investigación-acción. Escuela Técnica Superior de Ingeniería Informática: Universidad de Sevilla.

Novak, J. D. (2004). La teoría del aprendizaje significativo. Technology, 1-10.

Plumed, R., Calleja, P. C., Varley, P. A., \& Martin, R. (2013). From Sketches to CAM Models: Perceiving Pockets and Steps in Single-view Wireframe Sketches of Polyhedral Shapes (pp. 951-958). In: Proceedings of International Joint Conference on Pervasive and Ubiquitous Computing.

Riel, M. (2010). Understanding action research. Center for Collaborative Action Research, 43, 435-437. doi:10.1016/j. pragma.2010.08.016

Riel, M., \& Whitehead, J. (2011). Paper presented at annual meeting of the American Educational Research Association: Action Research Identity Outcomes: Shift in Self-Perception, Professional Role, and Researcher Identity Interactive Symposium. New: Orleans. A meta-analysis of the outcomes of action research.

Rossignac, J. (2004). Education-driven research in CAD. Computer-Aided Design, 36(14), 1461-1469. doi:10.1016/j.cad. 2003.10.008

Rubio García, R., Gallego Santos, R., \& Suárez Quirós, J. (2005). Present state of CAD teaching in Spanish Universities. Comparative Education, 44(3), 201-215. doi:10.1016/j.compedu.2003.09.003

Rudduck, J., \& Hopkins, D. (1985). Research As a Basis for Teaching: Readings from the Work of Lawrence Stenhouse. London: Heinemann.

Sanmartí, N. (2007). 10 ideas clave. Graó, Barcelona: Evaluar para aprender.

Siegel, S. (1988). Nonparametric statistics for the behavioral sciences. New York: McGraw-Hill.

Vygotsky, L. S. (1978). Interaction between learning and development. Readings on the Development of Children, 23(3), 34-41.

Ye, X., Peng, W., Chen, Z., \& Cai, Y. Y. (2004). Today's students, tomorrow's engineers: an industrial perspective on CAD education. Computer-Aided Design, 36(14), 1451-1460. doi:10.1016/j.cad.2003.11.006

Zaphiris, P., \& loannou, A. (2014). Learning and Collaboration Technologies. Designing and Developing Novel Learning Experiences. doi:10.1007/978-3-319-07482-5

\section{Submit your manuscript to a SpringerOpen ${ }^{\circ}$ journal and benefit from:}

- Convenient online submission

- Rigorous peer review

- Immediate publication on acceptance

- Open access: articles freely available online

- High visibility within the field

- Retaining the copyright to your article 